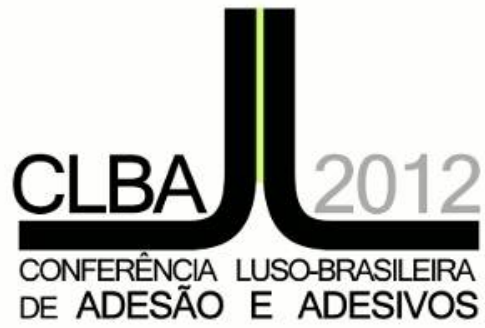

CLBA2012

8 e 9 de novembro Rio de Janeiro, Brasil Associação Brasileira de Adesão e Adesivos - ABAA Associação Portuguesa de Adesão e Adesivos - APAA http://clba.cefet-rj.br

\title{
Adhesive bond strength development evaluation using ABES in different lignocellulosic materials
}

\author{
J.M.Martins $^{1,4}$, J. Pereira ${ }^{1,2}$, C. Coelho ${ }^{1,4}$, J. Ferra ${ }^{3}$, F.D. Magalhães ${ }^{1}$, L.H. Carvalho ${ }^{1,4}$ \\ ${ }^{1}$ LEPAE, Universidade do Porto, Faculdade de Engenharia, 4200-465, Porto, Portugal. \\ ${ }^{2}$ Associação Rede de Competências em Polímeros, 4200-465, Porto, Portugal. \\ ${ }^{3}$ EuroResinas - Indústrias Químicas, S.A., 7520-064, Sines, Portugal \\ ${ }^{4}$ DEMad, Instituto Politécnico de Viseu, 3504-510, Viseu, Portugal
}

Adhesion phenomena are involved in several industrial processes found in the wood industry, such as the manufacturing of wood-based panels, cork composites and high pressure laminates, as well as in the surfacing of wood-based panels with wood veneer, impregnated paper or high pressure laminate. Portuguese companies are both the largest worldwide producers of cork composites and one of the most important players in the wood based panels sectors. The bonding process with thermosetting resins, usually carried out in a hot-press, is quite complex as it involves simultaneous and coupled heat and mass transfer, adhesive polymerization and complex mechanical and rheological behaviors [1], [2]. The dynamics of adhesive curing and bond strength development during the hot-pressing process affects production speed, energy consumption and product quality. The optimization of those industrial processes has been carried out so far based on trial and error. Therefore, the development of predictive models that properly describe the adhesive curing process is important to improve product quality and longterm performance. ABES equipment (Automated Bonding Evaluation System) [3] has already shown to be an excellent tool for evaluating the bonding performance of UF adhesives [4,5,6]. This paper presents a new application for ABES, which has been developed for determining the rate of strength development of adhesives during cure on wood lap shear joints. This equipment provides a quantitative means of understanding the 
dynamics of bond strength development under highly controlled conditions. It allows for accurate control of bonding pressure, platen temperature, and bonding dwell time and good alignment of the lap shear samples. To explore the reactivity of the different combinations (adhesive-cork, impregnate paper-wood and laminate-wood), a new sample configuration and a new kinetic model are proposed. Isothermal bond strength development was plotted as a function of time for several platen temperatures and the kinetic parameters were computed from these plot families, for each type of adhesive and combinations.

[1] L. Carvalho, in Core Document of COST E34 "Bonding of Timber”, Lignovisionen issue 18, p.197 (Universität für Bodenkultur, Wien, 2008).

[2] M. Sernek and M. Dunky, in "Wood-based Panels: An Introduction to Specialists", p.203, H. Thoemen, M. Irle and M. Sernek, eds. (Brunel University Press, London, England, 2010).

[3] J. Ferra, M. Ohlmeyer, A. Mendes, M.R. Costa, L.H. Carvalho and F. Magalhães, Int. J. Adhes. Adhes., 31(3), 127 (2011)

[4] N. Costa, J. Pereira, J. Martins, J. Ferra, P. Cruz, F. Magalhães, A. Mendes, L. Carvalho, Int. J. Adhes. Adhes., 33, 56 (2012)

[5] J. Martins, C. Coelho, J. Ferra, P. Cruz, L. Carvalho, Int. Wood Prod. J., 3, 31 (2012)

[6] P. Humphrey, US Patent 5176028 (1993) 